\section{穴 Heighten Science \\ P U B L I C I T I O N S Corporation}

ISSN

2637-3793
*Address for Correspondence: Sujit K

Bhattacharya, Senior Medicine Specialist, Glocal Hospital, Kolkata, India, Tel: 8697462003; Email: sujitkbhattacharya@yahoo.com

Submitted: 30 September 2018

Approved: 12 October 2018

Published: 13 October 2018

Copyright: @ 2018 Bhattacharya SK. This is an open access article distributed under the Creative Commons Attribution License, which permits unrestricted use, distribution, and reproduction in any medium, provided the original work is properly cited

\title{
A rare case of Diabetic Foot in male of middle age has been shown Diabetic foot
}

\author{
Sujit K Bhattacharya* \\ Senior Medicine Specialist, Glocal Hospital, Kolkata, India
}

\section{Abstract}

A rare case of Diabetic Foot in male of middle age has been shown.

\section{Text}

Diabetes mellitus is a chronic disease due to complete absence of its hormone, Insulin, or has the hormone which is ineffective. This disease affects individuals of all ages and both sexes. When the disease affects individuals below 40 years of age and there is complete absence of Insulin (autoimmune reaction), the disease is known as type 1 Diabetes mellitus. On the other hand the disease when it affects individual above the age of 40 years and there is partial deficiency of insulin, it is known as type 2 Diabetes mellitus. However, this age division is no longer used; instead it is called Mutuality Onset Diabetes mellitus in Adults (MODY). The accompanying picture shows a diabetic foot with a big blister full of blood. This type of presentation of Diabetic foot is relatively rare. Upon incision of the swelling, reddish pus came out. Draining of the pus and debridement of dead tissue was done under antibiotic coverage along with Insulin. The patient had a slow recovery. Strict control of diabetic status was done. Culture of the pus yielded staphylococcus aureus sensitive to amoxyclav, gentamycin and oflaxacin. Antibiotic treatment was continues for 10 days. Although this time the patient recovered, he was advised to take scrupulous care of the feet and control blood sugar.

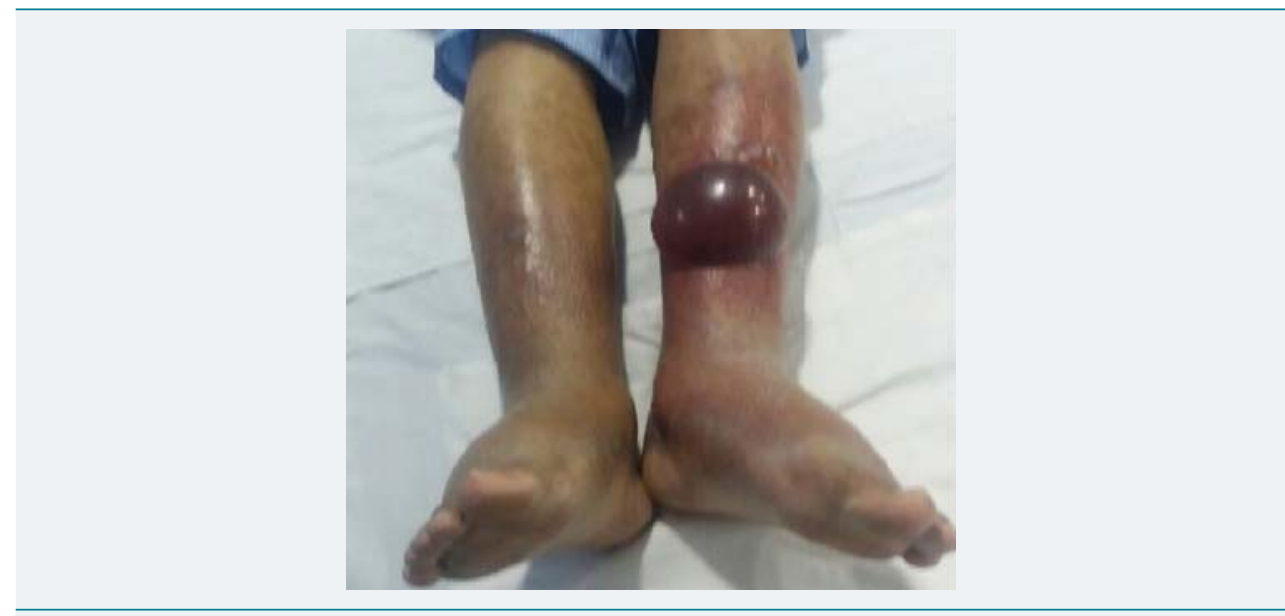

Figure 1: A rare case of Diabetic Foot in male of middle age has been shown. 